\title{
Petrophysical Evaluation of a Severely Heterogeneous Carbonate Reservoir; Electrical Image Logs Usage in Porosity Estimation
}

\author{
Mohsen Ezati*, Hedayat Olfati, Mojtaba Khadem, Mohammad Reza Yazdanipour, \\ Aisan Mohammad
}

SeaLand Engineering and Well Services, Tehran, Iran

Email: *m.ezati@sealandws.com

How to cite this paper: Ezati, M., Olfati, H., Khadem, M., Yazdanipour, M.R. and Mohammad, A. (2019) Petrophysical Evaluation of a Severely Heterogeneous Carbonate Reservoir; Electrical Image Logs Usage in Porosity Estimation. Open Journal of Geology, 9, 193-200.

https://doi.org/10.4236/ojg.2019.93013

Received: February 12, 2019

Accepted: March 23, 2019

Published: March 26, 2019

Copyright $\odot 2019$ by author(s) and Scientific Research Publishing Inc. This work is licensed under the Creative Commons Attribution International License (CC BY 4.0).

http://creativecommons.org/licenses/by/4.0/

\section{c) (i) Open Access}

\begin{abstract}
Image logs have higher resolution than conventional logs and it makes them powerful tools for detailed reservoir characterization and modeling. Hence, thin beds, which are not detectable using conventional logs, can be characterized by image log data. The present study focuses on the Permian-Triassic carbonate reservoirs of Dalan and Kangan formations in one of the gas fields in southern Iran. In this study, the reservoir porosity was estimated using Fullbore Formation Microimager (FMI) image log. Then, the results were compared and validated with the core data. Porosity was estimated as 2-dimentional image by rescaling the FMI image log with Micro-Spherical Focused Log (MSFL). The image log-derived porosity was then compared with conventional logs-derived and core porosities. The image log-derived porosity is in good agreement with the core data. In this paper, a procedure was introduced which can be used to recognize very narrow pay layers (thickness in centimeters). This work is very important for identifying the proper perforation intervals in heterogeneous reservoirs.
\end{abstract}

\section{Keywords}

Image Log, Porosity, Core Data, Dalan-Kangan Formations

\section{Introduction}

One of the main goals in evaluation of hydrocarbon fields is the generation of detailed reservoir model. Such model requires fine-scale data such as porosity and permeability that should be accurately used in the model; hence, image logs, by their higher resolutions, can be regarded for this aims. Image logs have been 
widely used in natural fractures' characterization [1]-[9] and borehole failures' detection for geomechanical modeling [10]-[15], but less used in petrophysical evaluations.

In the following, a number of petrophysical uses of image logs are presented. Some of the cases used image logs to estimate reservoir permeability. Classification and clustering methods were used by some of the authors to estimate permeability from image logs [16] [17]. Also, cementation factor (m) was estimated as a continuous curve from borehole images and petrophysical logs [18] and shale volume calculated using binarization technique by electrical image logs [19]. Furthermore, in some studies it was attempted to separate and calculate vuggy porosity using electrical image logs [20] [21]. But the purpose of this study is to determine the effective porosity (primary and secondary porosities) using electrical image logs. The results of this study are vital to determine the sudden changes of porosity, which happen in a few centimeters, in reservoir units of Dalan and Kangan formations. The mentioned reservoirs are very heterogeneous, so tiny porous-permeable parts are vital to be detected for perforation jobs.

This study was done in a carbonate gas reservoir located in southern Iran. No natural fracture was recorded over the studied interval and the essential permeability is supplied by interparticle and intercrystaline porosities. In this study FMI image log, Fullset logs and core data were used for porosity estimation by different methods and comparisons.

\section{Geological Setting}

The studied onshore gas field is located in northeastern Arabian Plate, based on the geological classifications. In the northern Arabian Plate, the Permian-Triassic successions are dominated by thick shallow-marine carbonate-evaporite sediments which developed on a passive margin of Gondwana [22]. In the studied field, the Dalan and Kangan formations geometry is stratiform or "layer-cake" [23]. In south of Iran, the Permian-Triassic succession is referred to as the Dalan and Kangan formations (Figure 1) which are equivalents of the Khuff Formation in the southern Arabian countries [24]. The Late Permian Dalan Formation is divided into limestone and dolostone members separated by the Nar member [25], (Figure 1). This formation is overlain by the Early Triassic Kangan Formation [26]. The Dalan-Kangan succession can be divided into five reservoir units, namely K1 to K5 (Figure 1), based on lithological variations [24]. In this study, theK1 to K4 reservoir units were focused for porosity estimation using FMI image log.

\section{Materials and Methods}

\subsection{Electrical Image Logs}

Image logs have much more resolution than conventional well logs. So, more detailed interpretation of the wellbore wall can be achieved using them. 


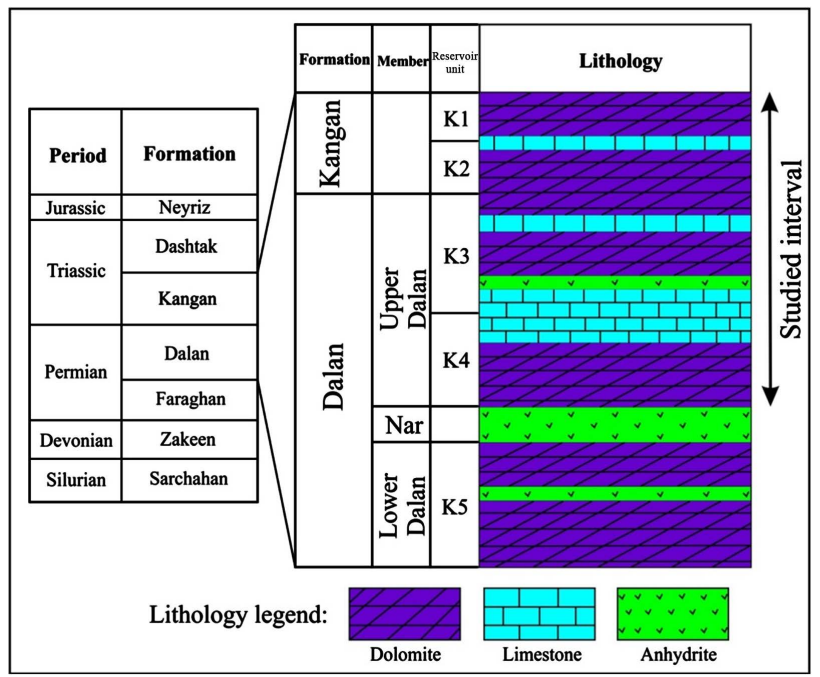

Figure 1. Stratigraphic column of studied formations (Dalan-Kangan) in southern Iran. Reservoir units of these formations are also shown along with lithological variations (modified from Rahimpour-Bonab et al., 2014).

Electrical image logs allow continuous observation of detailed vertical and lateral variations in formation properties. The vertical resolution of electrical image logs are $0.2 \mathrm{in.}$ ( $5 \mathrm{~mm}$ ) which is much more than the conventional well logs [27]. The observation and analysis of images provide information related to changes in rock composition, texture, structure and fluid content [27].

\subsection{Image Rescaling}

The pixel digits of the electrical image logs are relative but absolute resistivity values are required for petrophysical estimations using image logs. So, the relative digits of image should be calibrated into absolute resistivity values by using shallow resistivity logs. Image rescaling is an approach to calibrate image data with a shallow reading resistivity log. The scaled image has important applications for quantitative image analysis such as fracture aperture estimation, thin bed evaluation, porosity computation and permeability analysis.

Electrical image logs are composed of two-dimensional array digits whereas conventional well logs are 1-Dimentional. FMI image log has 192 reading (8 pads and flaps that each have 24 sensors) for each of the sampling depths, whereas Fullset logs have one reading for each of the sampling depths. So, the image should be transformed into 1-D quantity by averaging each of image rows (Image-Mean) for comparison to the conventional logs.

Calibration logs are shallow resistivity logs like MSFL or LLS. The shallowest resistivity log can be a better choice for image rescaling because the depth of investigation of FMI image is very low (1 inch), but in some cases like bad-hole condition, MSFL may be contains invalid digits. Therefore, LLS log can be used instead of MSFL. In this study, the raw FMI image (Image Raw Mean) rescaled to absolute digits of resistivity by using the MSFL Log (Figure 2). The vertical resolution of MSFL and FMI are 4 and 0.2 in., respectively. So, the Image Raw 
Mean curve was upscaled by 20 orders for matching of the two curves in regression cross plot (Figure 2). As can be seen in Figure 2, there is an exponential relationship between the MSFL and the average of raw image. Raw image can be rescaled to the absolute digits of resistivity by the relationship between MSFL and the average of raw image (Figure 3 ). In Figure 3, the raw image varies from 65 to 100 , whereas scaled image range is 0.2 to 2000 which shows the logarithmic nature of this image.

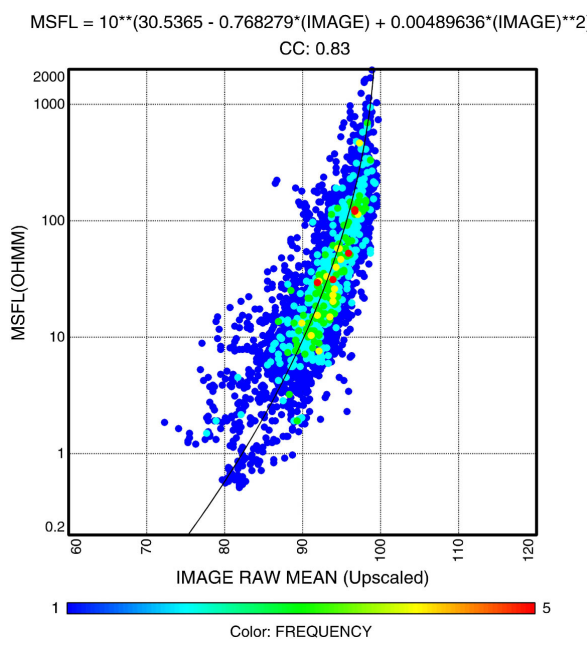

Figure 2. Crossplot of IMAGE RAW MEAN and MSFL logs. For making the resolutions more Comparable, the IMAGE RAW MEAN curve is upscaled by 20 orders. There is an exponential relationship between the IMAGE RAW MEAN and MSFL curves.

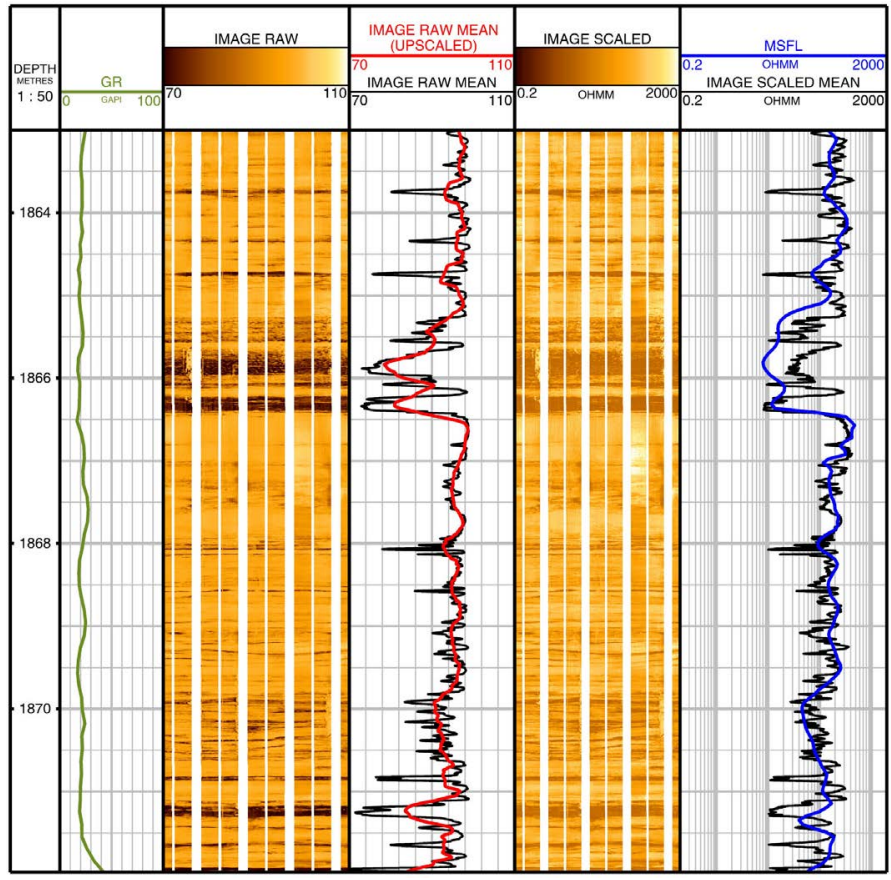

Figure 3. Image rescaling results. Image-Scaled was calibrated as logarithmic digits (pixels) by MSFL log and now its nature is like resistivity logs. The Image-Scaled-Mean log is in good agreement with MSFL (right track). 


\subsection{Porosity Estimation}

Electrical images are conductivity (or resistivity) map of the borehole wall within the flushed zone. Resistivity data from the electrical images is measured in the flushed zone of the borehole. So, the calibrated image (inputted as Rxo in following formula), can be transformed into porosity image of the wellbore wall by using Archie equation [28]. The Archie saturation equation in the flushed zone is:

$$
\mathrm{Sxo}^{\mathrm{n}}=\frac{\mathrm{Rmf}}{\Phi^{\mathrm{m}} \times \mathrm{Rxo}}
$$

By transforming the above equation:

$$
\Phi=\left(\frac{\mathrm{Rmf}}{\mathrm{Sxo}^{\mathrm{n}} \times \mathrm{Rxo}}\right)^{\frac{1}{\mathrm{~m}}}
$$

where, Sxo $=$ Water Saturation, $\mathrm{Rmf}=$ Resistivity of Mud Filtrate, $\Phi=$ Porosity, $\mathrm{Rxo}=$ Resistivity of Flushed Zone (Image-Scaled), $\mathrm{m}=$ Cementation Factor and $\mathrm{n}=$ Saturation Exponent.

Then, Image-Scaled can be transformed into porosity image by using the Archie equation and mentioned petrophysical parameters (Figure 4).

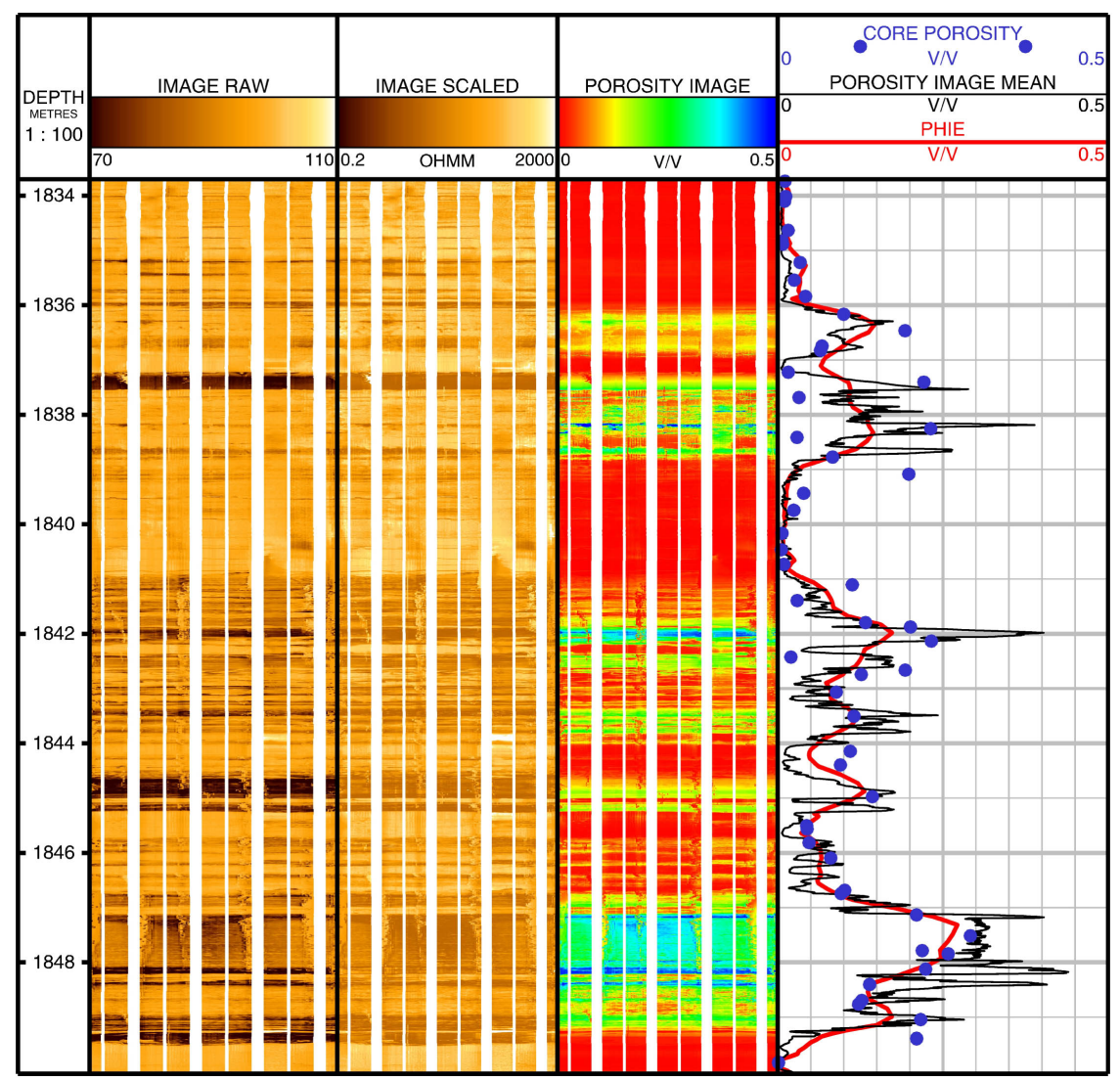

Figure 4. Estimated porosity image using Archie equation and its correlation with the other porosity calculation methods. Thin porous thin beds are detected by image log derived porosity which me be masked by conventional logs due to their lower resolutions. 


\section{Discussion}

Porosity-Image-Mean curve was calculated by averaging from the rows of Porosity-Image. So, image-derived porosity can be comparable with the other porosity calculation methods such as core data and neutron-density porosity (PHIE). As can be seen in Figure 4 there is a good correlation between the image-derived and the core porosities. More spikiness of Porosity-Image-Mean curve is related to higher resolution of image logs than conventional logs. The vertical resolution of conventional well logs is about 2 feet, so, they cannot detect layers which have thickness less than their resolution and they miss thin layers properties by averaging phenomenon [29].

As can be seen in Figure 4, in 1836 - $1838 \mathrm{~m}$ and 1842 - $1844 \mathrm{~m}$ depth intervals, there are some thin beds with high porosity which are detectable by Porosity-Image-Mean curve and validated by core data, but cannot be detected on PHIE curve.

\section{Conclusion}

An evaluation of porosity data has been done in a gas reservoir (Dalan-Kangan formations) in southern Iran, using the FMI image log. Then, the estimated porosity was compared and validated with other petrophysical logs (i.e. PHIE) and core data. The narrow porous-permeable layers can be detectable by integration of electrical image logs with the conventional logs. These layers are not identifiable using Fullset logs because of their low resolution. Coring process costs too much and usually their recovery are not complete. Hence, electrical image logs can be regarded for petrophysical parameters' extraction as continuous curves, economically. This proposed method can be used for the low resistivity pay zones in the future works. The low resistivity pay zones, which are not detectable by conventional logs, can be triggered utilizing image logs resolution.

\section{Acknowledgements}

The authors appreciate SeaLand Engineering and Well Services (SLD) for the data providing and financial support.

\section{Conflicts of Interest}

The authors declare no conflicts of interest regarding the publication of this paper.

\section{References}

[1] Paillet, F.L., Keys, W.S. and Hess, A.E. (1985) Effects of Lithology on Televiewer-Log Quality and Fracture Interpretation. SPWLA 26th Annual Logging Symposium, Dallas, 17-20 June 1985, 1-31.

[2] Paillet, F.L. (1993) Using Borehole Geophysics and Cross-Borehole Flow Testing to Define Hydraulic Connections between Fracture Zones in Bedrock Aquifers. Journal of Applied Geophysics, 30, 261-279.

https://doi.org/10.1016/0926-9851(93)90036-X 
[3] Hennings, P.H., Olson, J.E. and Thompson, L.B. (2000) Combining Outcrop Data and Three-Dimensional Structural Models to Characterize Fractured Reservoirs: An Example from Wyoming. AAPG Bulletin, 84, 830-849

[4] Prioul, R. and Jocker, J. (2009) Fracture Characterization at Multiple Scales Using Borehole Images, Sonic Logs, and Walkaround Vertical Seismic Profile. AAPG Bulletin, 93, 1503-1516.

[5] Ja'fari, A., Kadkhodaie-Ilkhchi, A., Sharghi, Y. and Ghanavati, K. (2011) Fracture Density Estimation from Petrophysical Log Data Using the Adaptive Neuro-Fuzzy Inference System. Journal of Geophysics and Engineering, 9, 105-114. https://doi.org/10.1088/1742-2132/9/1/013

[6] Ezati, M., Soleimani, B. and Moazeni, M.S. (2014) Fracture and Horizontal Stress Analysis of Dalan Formation Using FMI Image Log in One of Southwestern Iranian Oil Wells. Journal of Tethys, 2, 1-8.

[7] Kosari, E., Ghareh-Cheloo, S., Kadkhodaie-Ilkhchi, A. and Bahroudi, A. (2015) Fracture Characterization by Fusion of Geophysical and Geomechanical Data: A Case Study from the Asmari Reservoir, the Central Zagros Fold-Thrust Belt. Journal of Geophysics and Engineering, 12, 130-143. https://doi.org/10.1088/1742-2132/12/1/130

[8] Ezati, M., Azizzadeh, M., Riahi, M.A., Fattahpour, V. and Honarmand, J. (2018) Characterization of Micro-Fractures in Carbonate Sarvak Reservoir, Using Petrophysical and Geological Data, SW Iran. Journal of Petroleum Science and Engineering, 170, 675-695. https://doi.org/10.1016/j.petrol.2018.06.058

[9] Lai, J., Wang, G.W., Fan, Z.Y., Wang, Z.Y., Chen, J., Zhou, Z.L., Wang, S.C. and Xiao, C.W. (2017) Fracture Detection in Oil-Based Drilling Mud Using a Combination of Borehole Image and Sonic Logs. Marine and Petroleum Geology, 84, 195-214. https://doi.org/10.1016/j.marpetgeo.2017.03.035

[10] Aadnoy, B.S. (1990) In-Situ Stress Directions from Borehole Fracture Traces Journal of Petroleum Science and Engineering, 4, 143-153.

https://doi.org/10.1016/0920-4105(90)90022-U

[11] Aadnoy, B.S. and Bell, J.S. (1998) Classification of Drilling-Induced Fractures and Their Relationship to in-Situ Stress Directions The Log Analyst, 39, 27-42.

[12] Zoback, M.D., Barton, C.A., Brudy, M., Castillo, D.A., Finkbeiner, T., Grollimund, B.R., Moos, D.B., Peska, P., Ward, C.D. and Wiprut, D.J. (2003) Determination of Stress Orientation and Magnitude in Deep Wells. International Journal of Rock Mechanics and Mining Sciences, 40, 1049-1076. https://doi.org/10.1016/j.ijrmms.2003.07.001

[13] Barton, C. and Moos, D. (2010). Geomechanical Wellbore Imaging: Key to Managing the Asset Life Cycle. AAPG Memoir, 92, 81-112.

[14] Kidambi, T. and Kumar, G.S. (2016) Mechanical Earth Modeling for a Vertical Well Drilled in a Naturally Fractured Tight Carbonate Gas Reservoir in the Persian Gulf. Journal of Petroleum Science and Engineering, 141, 38-51. https://doi.org/10.1016/j.petrol.2016.01.003

[15] Rajabi, M., Tingay, M., King, R. and Heidbach, O. (2017) Present-Day Stress Orientation in the Clarence-Moreton Basin of New South Wales, Australia: A New High Density Dataset Reveals Local Stress Rotations. Basin Research, 29, 622-640. https://doi.org/10.1111/bre.12175

[16] Knecht, L., Mathis, B., Leduc, J., Vandenabeele, T. and Di Cuia, R. (2004) Electrofacies and Permeability Modeling in Carbonate Reservoirs Using Image Texture 
Analysis and Clustering Tools. Petrophysics, 45, 27-37.

[17] Al-Khatib, H., Mirotchnik, K. and Jonkers, J. (2013) Petrophysical and Geological Evaluation of Laminated Clastic Rocks Using Borehole Electrical Image and NMR Data Integration. SPE Annual Technical Conference and Exhibition, New Orleans, 30 September-2 October 2013, 1-16.

[18] Akbar, M., Steckhan, J., Tamimi, M., Zhang, T. and Saner, S. (2008) Estimating Cementation Factor (m) for Carbonates Using Borehole Images and Logs. Abu Dhabi International Petroleum Exhibition and Conference, Abu Dhabi, 3-6 November 2008, 1-10.

[19] Ezati, M., Soleimani, B., Khoshbakht, F. and Moazeni, M. (2015) Shale Volume Estimation Using FMI Image Logs. Petroleum Research, 24, 170-174.

[20] Alvarez, P., Rangel, J. and Martinez, M. (2009) Mapping Porosity Distribution in a Vuggy Carbonate Reservoir Integrating Seismic Attributes with Borehole Image Logs through a Supervised Facies Analysis. SEG, 1, 1880-1884.

[21] Pal, A., Seth, K., Guru, U.K., Tiwari, R.R. and Dasgupta, D. (2007) Porosity Partitioning and Flow Unit Characterization from an Integration of Magnetic Resonance and Borehole Image Measurements. SPE Middle East Oil and Gas Show and Conference, Manama, 11-14 March 2007, 1-7.

[22] Edgell, H.S. (1996) Salt Tectonism in the Persian Gulf Basin. Geological Society, London, Special Publications, 100, 129-151.

https://doi.org/10.1144/GSL.SP.1996.100.01.10

[23] Enayati-Bidgoli, A.H., Rahimpour-Bonab, H. and Mehrabi, H. (2014) Flow Unit Characterisation in the Permian-Triassic Carbonate Reservoir Succession at South Pars Gasfield, Offshore Iran. Journal of Petroelum Geology, 37, 205-230. https://doi.org/10.1111/jpg.12580

[24] Alsharhan, A.S. (2006) Sedimentological Character and Hydrocarbon Parameters of the Middle Permian to Early Triassic Khuff Formation, United Arab Emirates. GeoArabia, 11, 121-158.

[25] Edgell, H.S. (1977) The Permian System as an Oil and Gas Reservoir in Iran, Iraq and Arabia. Second Iranian Geological Symposium (Tehran), Tehran, 161-201.

[26] Szabo, F. and Kheradpir, A. (1978) Permian and Triassic Stratigraphy, Zagros Basin, South-West Iran. Journal of Petroelum Geology, 1, 57-82. https://doi.org/10.1111/j.1747-5457.1978.tb00611.x

[27] Serra, O. (1989) Formation Microscanner Image Interpretation. Schlumberger Educational Services, Houston, TX.

[28] Archie, G.E. (1942) The Electrical Resistivity Log as an Aid in Determining Some Reservoir Characteristics. Transactions of the Metallurgical Society of AIME, 146, 54-62.

[29] Ellis, D.V. and Singer, J.M. (2007) Well Logging for Earth Scientists. Springer, Dordrecht. https://doi.org/10.1007/978-1-4020-4602-5 